\title{
Small rodent cycles influence interactions among predators in a boreal forest ecosystem
}

\author{
Rocío Cano-Martínez $^{1}$ [D $\cdot$ David Carricondo-Sanchez ${ }^{1} \cdot$ Olivier Devineau $^{1} \cdot$ Morten Odden $^{1}$
}

Received: 25 June 2020 / Accepted: 27 July 2021 / Published online: 18 August 2021

(c) The Author(s) 2021

\begin{abstract}
Cyclic fluctuations of prey have profound effects on the functioning of ecosystems, for example, by changing the dynamics, behavior, and intraguild interactions of predators. The aim of this study was to assess the effect of rodent cyclic fluctuations in the interspecific interactions of a guild of small- and medium-sized predators: red fox (Vulpes vulpes), pine marten (Martes martes), and weasels (Mustela erminea and Mustela nivalis) in the boreal ecosystem. We analyzed eight years (2007-2014) of snow tracking data from southeastern Norway using structural equation models to assess hypothesized networks of causal relationships. Our results show that fluctuations in rodent abundance alter the strength of predator's interactions, as well as the effect of determinant environmental variables. Pine marten and weasel abundances were positively associated with rodent population growth rate, but not red fox abundance. All predators were positively associated with each other; however, the association between red fox and the other predators weakened when rodents increased. Rodent fluctuations had variable effects on the habitat use of the predators. The presence of agricultural land was important for all predators, but this importance weakened for the mustelids as rodent abundance increased. We discuss the shifting role of interference and exploitative competition as possible mechanisms behind these patterns. Overall, we highlight the importance of accounting for the dynamics of prey resources when studying interspecific interactions among predators. Additionally, we demonstrate the importance of monitoring the predator populations in order to anticipate undesirable outcomes such as increased generalist predator abundances to the detriment of specialists.
\end{abstract}

Keywords Intraguild interactions $\cdot$ Carnivore community $\cdot$ Population cycles $\cdot$ Competition $\cdot$ Structural equation models

\section{Introduction}

Cyclic fluctuations of small mammals are characteristic of northern ecosystems and have been comprehensively studied in the last century (Korpimäki and Krebs 1996; Krebs and Myers 1974; Norrdahl 1995). Since the classic 10-year population cycle of lynx (Lynx canadiensis) and snowshoe hares (Lepus americanus) was described in the boreal forest of North America (Elton and Nicholson 1942), numerous studies have reported cyclic population dynamics of a diverse group of animals around the world, such as voles

Communicated by Frank Langevelde.

Rocío Cano-Martínez

rocio.martinez@inn.no

1 Department of Forestry and Wildlife Management, Inland Norway University of Applied Sciences, Campus Evenstad, NO-2480 Koppang, Norway
(Microtus spp.) and lemmings (Lemmus spp.) (Korpimäki and Krebs 1996), ptarmigan (Lagopus spp.), black grouse (Tetrao tetrix), hazel grouse (Tetrastes bonasia) (Lindén 1988; Ranta et al. 1995; Watson et al. 1998), and forest Lepidoptera (Myers 1988). These population cycles have profound effects in the functioning of the ecosystems where they occur (Ims and Fuglei 2005; Stoessel et al. 2018), influencing the dynamics and behavior of predators (Klemola et al. 1999; Korpimäki et al. 1991) and of other sympatric herbivores (i.e., the Alternative Prey Hypothesis; Angelstam et al. 1984; Breisjøberget et al. 2018).

In these systems, different predators within a community can share the same fluctuating prey. For example, in Scandinavia, vole populations follow 3-4 year cycles, which makes them a variable food source for a number of predators (Hansson and Henttonen 1985). Changes in prey availability may then influence interspecific interactions (Henden et al. 2009a; Stoessel et al. 2018). These interactions are largely based on exploitation competition, which operates when a 
competitor limits the availability of some shared resources (Morin 2011), and on interference competition, which involves direct negative interactions between species such as intraguild predation (Palomares and Caro 1999; Polis and Holt 1992). This puts many predators in a landscape of fear similar to that experienced by their prey (Laundré et al. 2001) and forces them to choose less optimal habitats and to alter their activity patterns in order to avoid competition and predation risk (Bischof et al. 2014; Hunter and Caro 2008; Palomares et al. 1998).

Boreal ecosystems are expected to suffer an increased vulnerability to climate change and anthropogenic disturbances (Gauthier et al. 2015; Li et al. 2018), and carnivore communities are dramatically changing under these impacts (Elmhagen et al. 2015). While specialist predators are declining, generalist predators like the red fox (Vulpes vulpes) seem to be favored by climate warming (Hersteinsson and MacDonald 1992) and by the expansion of agricultural lands and anthropogenic infrastructures (Elmhagen et al. 2015; Kurki et al. 1998). Additionally, during the last decades, rodent cycles are fading out in some parts of Europe (Hörnfeldt et al. 2005) and returning in others (Brommer et al. 2010), which might affect the interactions of sympatric carnivores dependent on rodents and change their community structure. Thus, there is a need for an improved understanding of how interspecific interactions may change, so that we can manage these species under rapidly changing conditions (Henden et al. 2009b).

In order to investigate predator species interactions in connection with prey fluctuations, we studied a predator guild in the Scandinavian boreal forests: red fox and pine marten (Martes martes), considered generalist predators (Kurki et al. 1998), and stoats (Mustela erminea) and least weasels (Mustela nivalis), considered rodent specialists (King and Moors 1979; King and Powell 2007b; Storch et al. 1990). These species rely largely on rodents as their main prey, which implies a high potential for dietary overlap and competitive interactions (Jedrzejewski et al. 1989; King and Powell 2007b).

Other bottom-up factors influencing accessibility to both main and alternative prey may also play an important role in structuring predator populations. Snow depth can limit access to voles, reducing the predator-hunting success depending on their size and hunting strategy. For instance, both red fox and pine marten are more limited by snow depth (Willebrand et al. 2017) than small mustelids (King and Powell 2007a). During periods of reduced availability of rodents, both stoats and least weasels are still able to reach rodents in their burrows, possibly contributing to the crash phase of rodent population cycles in boreal ecosystems (the Specialist Predator Hypothesis; Hanski et al. 1993; Hansson and Henttonen 1985; King and Powell 2007b; Sundell et al. 2013). On the other hand, red fox and pine marten (generalist predators) increase the proportion of alternative prey species in their diets when small rodents are few or inaccessible (the Alternative Prey Hypothesis; Breisjøberget et al. 2018; Helldin 1999; Jedrzejewski and Jedrzejewska 1992; Pulliainen and Ollinmäki 1996), which might facilitate coexistence among these competitive species (Schoener 1974). Accordingly, a range of factors, including net primary productivity and human land use, may affect the accessibility to main and alternative prey, and thereby potentially influence interactions among coexisting predators (Jahren et al. 2020).

The aim of this research was to assess the impact of rodent cyclic fluctuations in the interactions of medium- and small-sized competing predators using 8 years (2007-2014) of snow tracking data. Specifically, we assessed the effect of rodent population growth on the strength of predator's interactions while accounting for the influence of determinant environmental variables, which can moderate the strength of these interactions (Elmhagen and Rushton 2007).

We hypothesize that the interspecific interactions among the mesopredator guild will change depending on rodent availability, following the rodent cycle. Exploitative competition is particularly important when dietary overlap is high and food availability is low. Under these circumstances, smaller predators are predicted to be more efficient at foraging than larger predators (Bagchi and Ritchie 2012). Stoats and least weasels are very well adapted to hunting small rodents, and at the same time, they can avoid predation by hiding under ground (King 1989). Therefore, in years of low rodent abundance, we expected weasels to have an advantage over red fox and pine marten (i.e., larger competitors), relaxing spatial avoidance and selecting areas preferred by rodents. On the other hand, red fox and pine marten will switch to alternative prey, thereby reducing interspecific competition (Angelstam et al. 1984; Randa et al. 2009).

During years of high rodent availability, red fox and pine marten will switch back to their main prey and interference competition may gain importance. Under strong interference competition pressure, larger competitors are usually in advantage (King 1989; Palomares and Caro 1999), and small-sized predators are more likely to use spatial avoidance as a coexistence strategy (Balme et al. 2017; Palomares et al. 2016). We therefore predict that, when rodent availability is high, small predators will avoid areas occupied by larger competitors in order to avoid aggressive interactions.

\section{Material and methods}

\section{Study area}

This study was carried out in Hedmark County $\left(27,400 \mathrm{~km}^{2}\right.$, $61^{\circ} \mathrm{N} 11^{\circ} \mathrm{E}$ ), southeastern Norway. The southern part of 
the county is characterized by agricultural fields intermixed with large forested areas, whereas the northern part is less productive with fragmented alpine areas (Fig. 1). Forests are dominated by conifers, mainly Scots pine (Pinus sylvestris) and Norway spruce (Picea abies), intermixed with deciduous species such as birch (Betula pubescens and B. pendula), rowan (Sorbus aucuparia), aspen (Populus tremula), gray alder (Alnus incana), and willow (Salix caprea). Elevation ranges from $140 \mathrm{~m}$ above sea level (asl) in the south to a maximum of $2180 \mathrm{~m}$ asl in the north. Mean annual temperatures decrease with latitude and altitude, and therefore, the duration of snow cover changes from south to north (Pedersen et al. 2017). Predators detected were red fox, pine marten, and weasels (which included stoat and least weasel). Lager predators are also present in the study area. However, brown bear (Ursus arctos) is hibernating in winter, and densities of lynx (Lynx lynx), wolverine (Gulo gulo), and wolf (Canis lupus) are low. Consequently, we found too few tracks from these predators to include them the study.

\section{Census data}

We used 585 snow tracking transects of $2.93 \mathrm{~km}( \pm 0.01 \mathrm{SE})$ length in average surveyed in January from 2007 to 2014 (Fig. 1) to estimate predator abundance. These transect lines were part of a Norwegian national monitoring program for large carnivores and were based on voluntary work from members of the Hedmark Chapter of the Norwegian
Fig. 1 Location of the centroids of small rodent survey areas (violet triangles) and predator snow transects (black dots) within Hedmark County, southeastern Norway

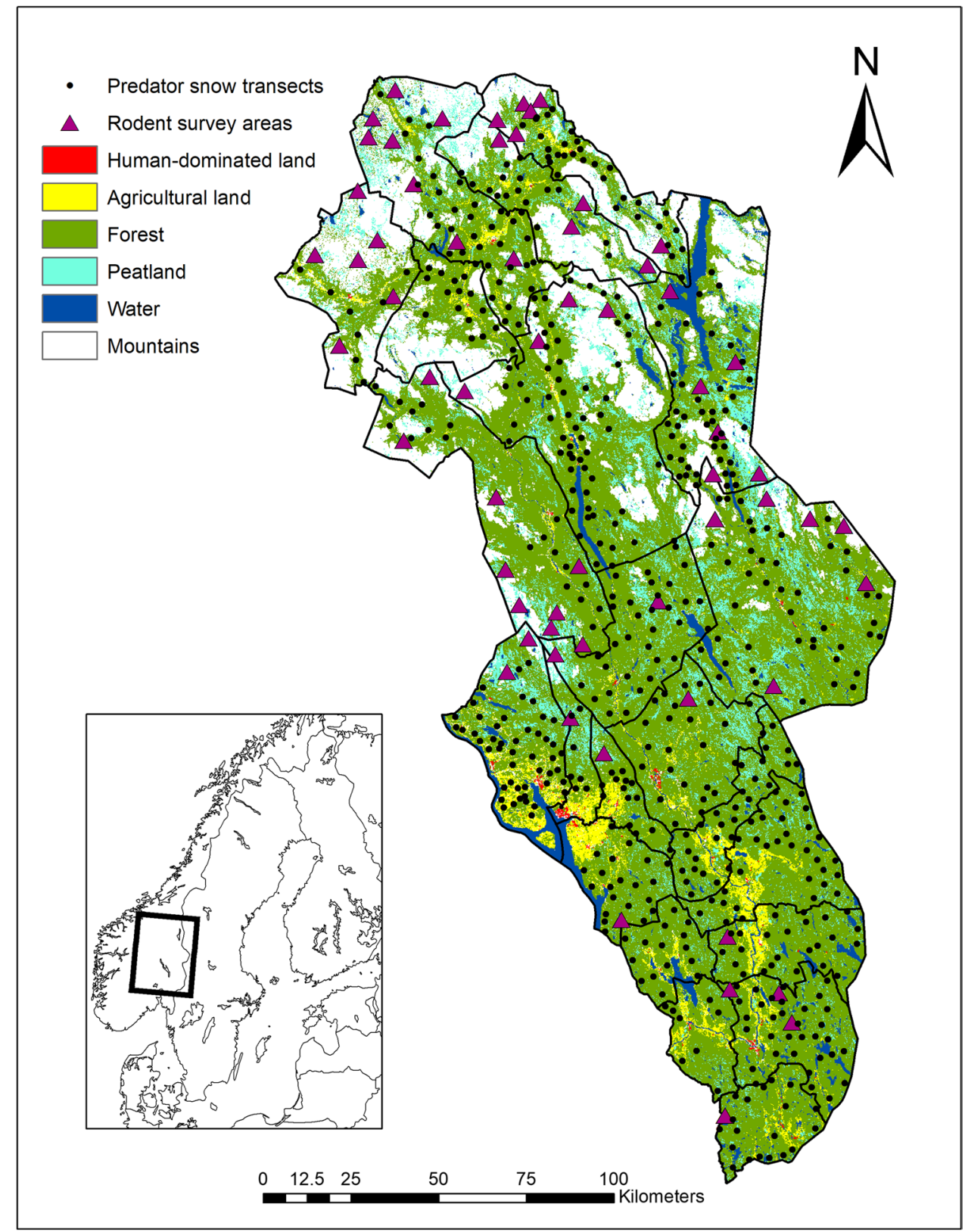


Association of Hunters and Anglers (Tovmo and Brøseth 2014). The transect line density was 3-4 lines per $100 \mathrm{~km}^{2}$ (Tovmo and Brøseth 2014). On average, 383.5 ( \pm 17.89 SE) transects were surveyed each year under favorable snow conditions (i.e., $3.4 \pm 0.02$ SE days since last snowfall). The number of wildlife tracks crossing the transect line was recorded for all species, together with snow depth and days since last snowfall. Tracks of stoat and least weasel were grouped together in order to reduce identification error given the difficulties to differentiate the tracks of both species in the field. Least weasels and stoats are referred to as "weasels" hereafter. An annual abundance index of predators was then calculated as the number of crossing tracks divided by transect kilometers and days since last snowfall.

Visual observations of rodents were obtained from line transect surveys of forest grouse species conducted in early August from 2006 to 2014 (Fig. 1). For each transect line, volunteers recorded whether small rodents had been observed. An average of six annual counts $(\mathrm{SD}=2.6)$ were conducted in 48 different survey areas (violet triangles on Fig. 1). The size of the survey plot averaged $56.0 \mathrm{~km}^{2}$ $(\mathrm{SD}=61.1)$, and in each area, an average of $15.4(\mathrm{SD}=10.9)$ transect lines $(\bar{x}=3.2 \mathrm{~km} \pm 1.1 \mathrm{SD})$ with a total length of $47.1 \mathrm{~km}(\mathrm{SD}=34.5)$ per survey plot were monitored (Breisjøberget et al. 2018). We calculated an index of small rodent abundance for each rodent survey area (Fig. 1) as the proportion of surveyed transects where rodents were observed (Breisjøberget et al. 2018). Since predator and rodent abundance estimates were obtained from transects that did not coincide in space, we interpolated rodent abundance index by using inverse distance weighting (IDW) in ArcGIS 10.3 (ESRI 2014) (Online Resource 1). We then extracted the interpolated rodent abundance value from each carnivore transect centroid and calculated rodent annual population growth as the difference between abundance index in year $t$ and abundance index in year $t-1\left(N_{t}-N_{t-1}\right)$, giving an index of population growth that ranges from-1 to 1 .

\section{Habitat data}

Snow tracking transects were related to habitat variables measured at their centroid point. These variables included elevation, latitude, relative density of human settlements, and relative density of agricultural fields, and they were obtained from digitized topographic land data from the Norwegian Mapping Authority (N250). We used the estimates for relative human settlements density and relative agricultural density calculated by Jahren et al. (2020) as follows: houses were transformed to a point layer that was later used to predict a planar kernel density map of relative settlement density. Kernel bandwidth was estimated by Gaussian approximation (Silverman 1986). Regarding the relative density of agricultural land, the geometrical center of agriculture fields was calculated and predicted planar kernel density by using agricultural-field size as $z$-value. Both estimated values, relative settlement density and relative agricultural density land, were then extracted to the transect centroid points.

\section{Statistical analysis}

All statistical analyses were carried out in $\mathrm{R}$ version 3.5.2 (www.r-project.com). We used Pearson's correlation tests to check for correlation among continuous environmental variables, with a limit of $r \geq 0.6$. Altitude and latitude were highly correlated (Pearson's $r=0.84$ ), and agriculture and house density were slightly correlated (Pearson's $r=0.6$ ). We decided to retain altitude and agriculture density for further modeling since they are important determinant factors for home range sizes and abundance of red foxes in Hedmark County (Jahren 2017; Walton et al. 2017).

Since the census data from carnivores and rodents were taken 4-5 months apart, i.e., August for rodents and January for carnivores, we used the index of rodent annual population growth from year $t$ to test the effect on the index of carnivore abundance on year $t+1$. In this way, we take into account the delay in the numerical response of predators to the abundance of their main prey (O'Mahony et al. 1999; Sundell et al. 2013). Therefore, we did not use carnivore data from year 2007 as we lacked rodent estimates to calculate rodent growth for year 2006.

We used structural equation modeling (SEM) to test how the interactions between competing predators changed in relation to the population growth of a shared prey. SEM provides a multivariate framework to develop and evaluate hypothesized networks of causal relationships, estimating the relative strength of direct and indirect paths within the system (Grace 2006; Grace et al. 2012).

We considered two alternative models, based on our predictions and on documented predator interactions in boreal ecosystems (Fig. 2). The first model represents a system where red fox interacts with weasels through pine marten (i.e., through an indirect pathway, Fig. 2a); while the second model represents a system where red fox interacts with weasels also through a direct pathway (Fig. 2b).

To construct the SEM, we used generalized linear mixed models with negative binomial distribution to model overdispersion in a Bayesian framework, using the brm function in the brms package (Bürkner 2017) in R. We used the number of predator tracks per transect line as the response variable. Explanatory variables included the following: (i) abundance index of competing predators and (ii) environmental variables, represented by agricultural land, snow depth, and altitude. Spatial and temporal correlations were controlled using municipality and year as random effects. In order to account for track length and track accumulation over 

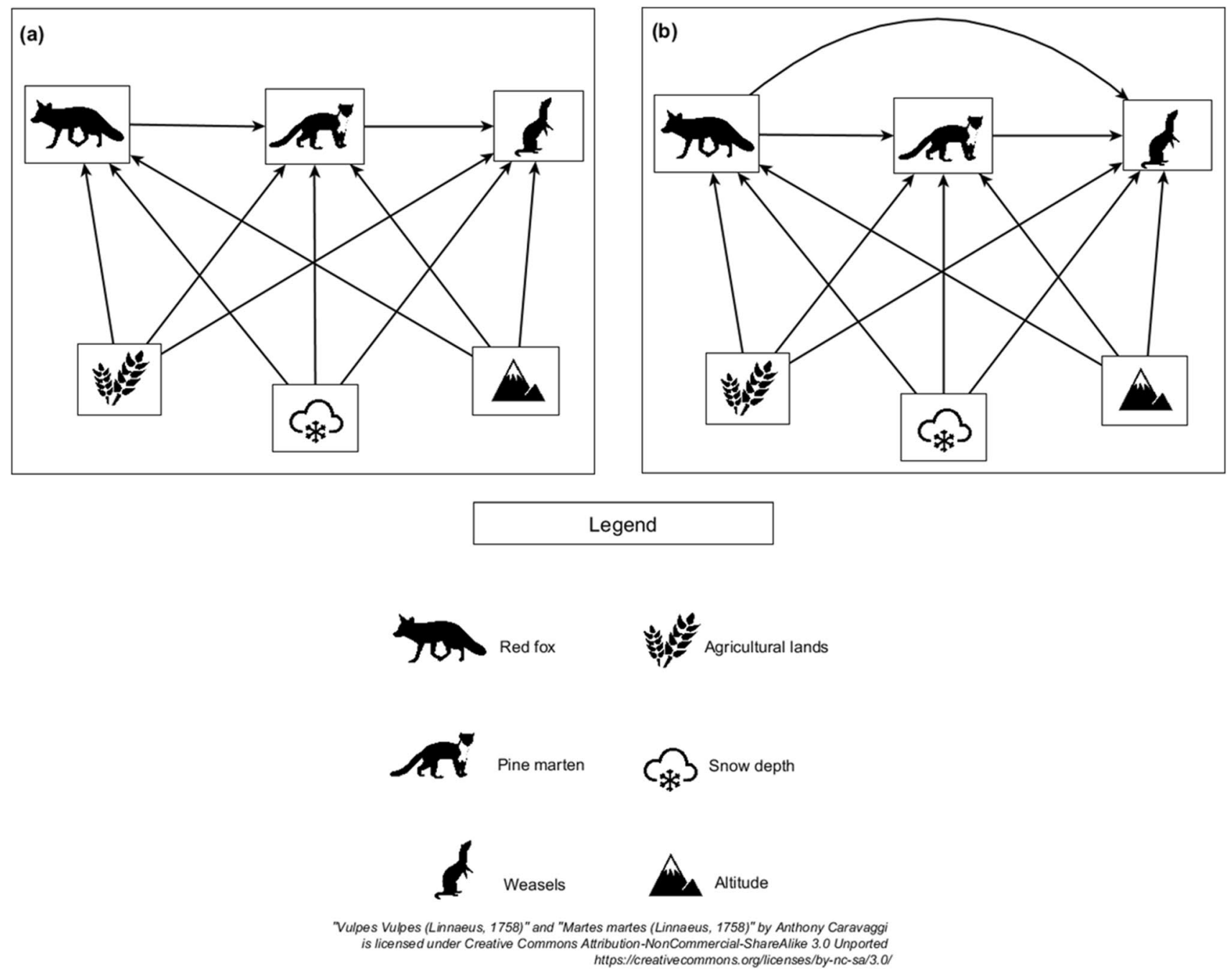

Fig. 2 Path diagrams representing two alternative structural equation models (SEM). Arrows represent the direction of hypothesized causal relationships between measured variables, where predators affect each other through different direct and indirect pathways. We

time, we included days since last snowfall and track length as offsets, thus effectively modeling the number of tracks per day per kilometer of transect (Hilbe 2014). In order to test the effect of rodent population growth in the different casual paths, we considered the interaction between rodent population growth and each of the fixed explanatory variables included in the models.

We used normal distributions with mean $=0$ and standard deviation $=10$ as weakly informative priors for the fixed variables and a $t$-Student distribution with three degrees of freedom as a non-informative prior for the random effects. We fitted the models using three chains and 3000 iterations, of which 1000 were discarded as warmup. We used leaveone-out cross-validation values using the function loo from package loo (Vehtari et al. 2019) as indicators of model fit and for model selection. We checked convergence by included the interaction of rodent growth with all the paths in each model; however, they are not represented in these diagrams for visual clarity

looking at the density distribution plots and with the Gelman and Rubin's convergence diagnostic $\hat{R}$ (Gelman and Rubin 1992). We also calculated a Bayesian $R^{2}$ (Gelman et al. 2018) for each model using the bayes_R2 function in the brms package (Bürkner 2017) to assess the variance explained by the fixed factors.

\section{Results}

In total, 15,257 red fox, 2752 pine marten, and 3164 weasel tracks were observed along $1713.78 \mathrm{~km}$ of transects during the 8-year survey. Two rodent peaks occurred during the study period: in 2011 and 2014 (Fig. 3). However, we only had carnivore data until the winter of 2014, so we could not test the effect of this last peak. The lowest mean rodent 


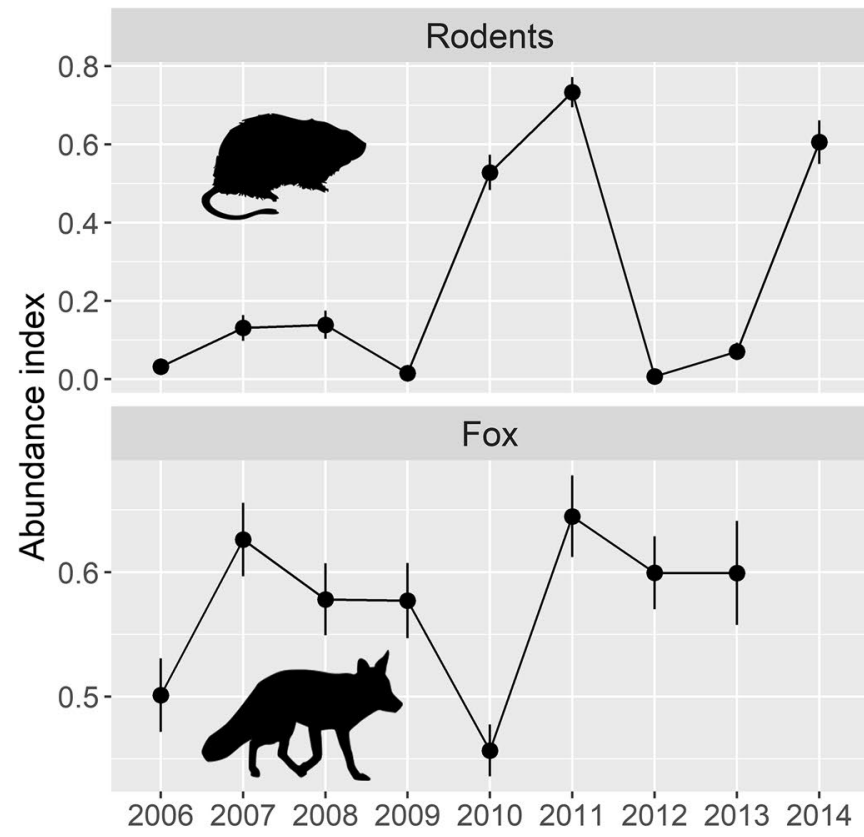

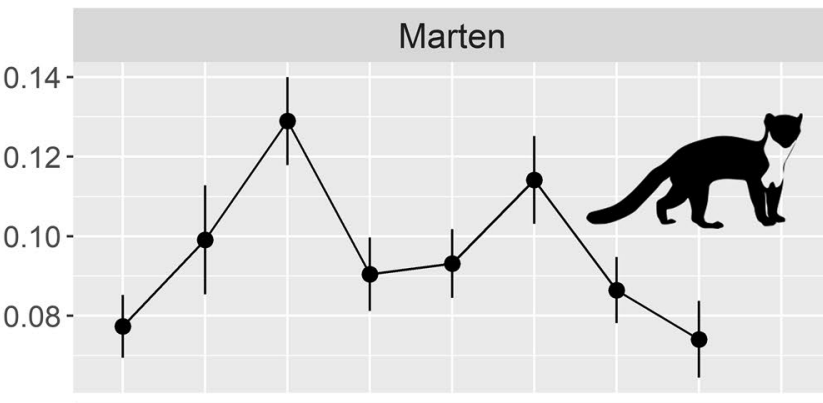

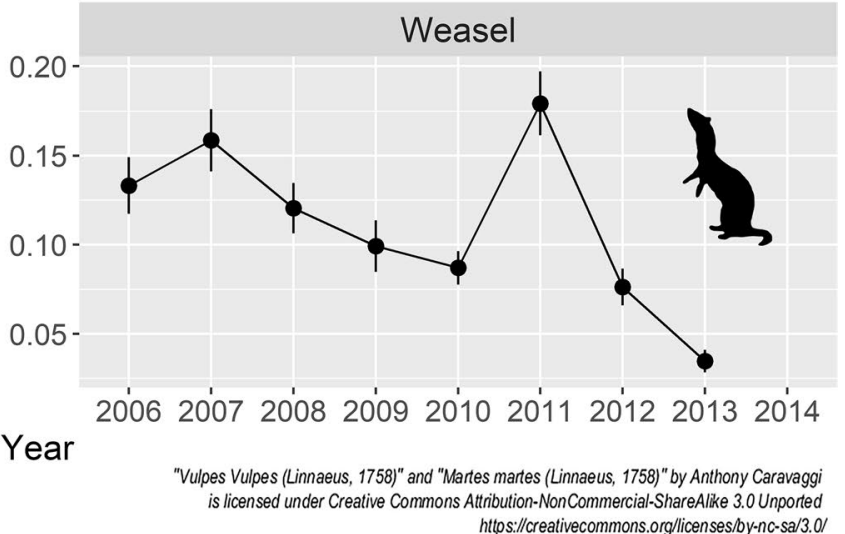

last snowfall and track length) $\pm 2 \mathrm{SE}$ during the whole study period (2006-2014). We aligned carnivore year with rodent year data collection (i.e., 4 to 5 months after rodent data collection) densities were observed in 2009 and 2012 (Fig. 3).The IDW results showed large-scale spatial synchrony of rodent cycles in Hedmark County among years (Online Resource 1).

Between the two models tested, the model with direct interactions between all predators (Fig. 2b) had the lowest $\mathrm{LOO}$ value ( $\mathrm{LOOIC}=26,642.80)$, followed by model a $(\Delta \mathrm{LOO}=+25.98$; Fig. $2 \mathrm{a})$. Therefore, we selected model b as the best fit for our data (Fig. 2b), with $R^{2}$ values of 0.28 for red fox, 0.35 for pine marten, and 0.49 for weasels. For interpretation, we only considered coefficients whose $80 \%$ credible intervals (CRI) did not overlap zero, and we described separately the coefficients for the direct associations (Fig. 4a) and the coefficients for the interaction with rodent growth (Fig. 4b). At the species level, pine marten and weasels abundances were positively associated with rodent population growth (mean posterior distribution of $0.20,80 \%$ CRI $[0.09,0.31]$ and $0.39,80 \%$ CRI [0.26, 0.53], respectively; Fig. 4a, Fig. 5). Red fox, on the other hand, did not show a clear association with rodent population growth (mean posterior distribution of $-0.02,80 \%$ CRI $[-0.06$, 0.03]) (Figs. 4a and 5).

Our best model showed positive direct associations among the three predators (Figs. $4 \mathrm{a}$ and 5). The density of agricultural lands showed a positive direct association with the three predator species, and snow depth showed a positive direct association only with pine marten. Altitude, on the other hand, showed a negative direct association with red fox and a positive direct association with pine marten (Figs. 4a and 5). Interestingly, these direct associations changed when we took into account the interaction with rodent growth (Figs. $4 \mathrm{~b}$ and 5). The positive relationship between red fox and the other smaller predators was reduced when rodent abundance increased. Likewise, the positive association of pine marten and weasels with agriculture lands became weaker when rodents where increasing. Altitude was also positively associated with red fox when rodents were increasing (Figs. $4 \mathrm{~b}$ and 5). For the detailed estimates of the final SEM, see Online Resource 2.

\section{Discussion}

In this study, we assessed whether interactions between sympatric predators in a boreal ecosystem are affected by the fluctuations of their shared cyclic prey. Our study shows that changes in prey resources modify how competing predators interact with each other, forcing them to adjust their competitive strategy depending on their diet specialization and competitive abilities. Pulsed resources have been shown to change the relative importance of top-down and bottomup drivers in various ecosystems and our results reinforce the hypothesis that cyclic prey resources affect interspecific 
(a)

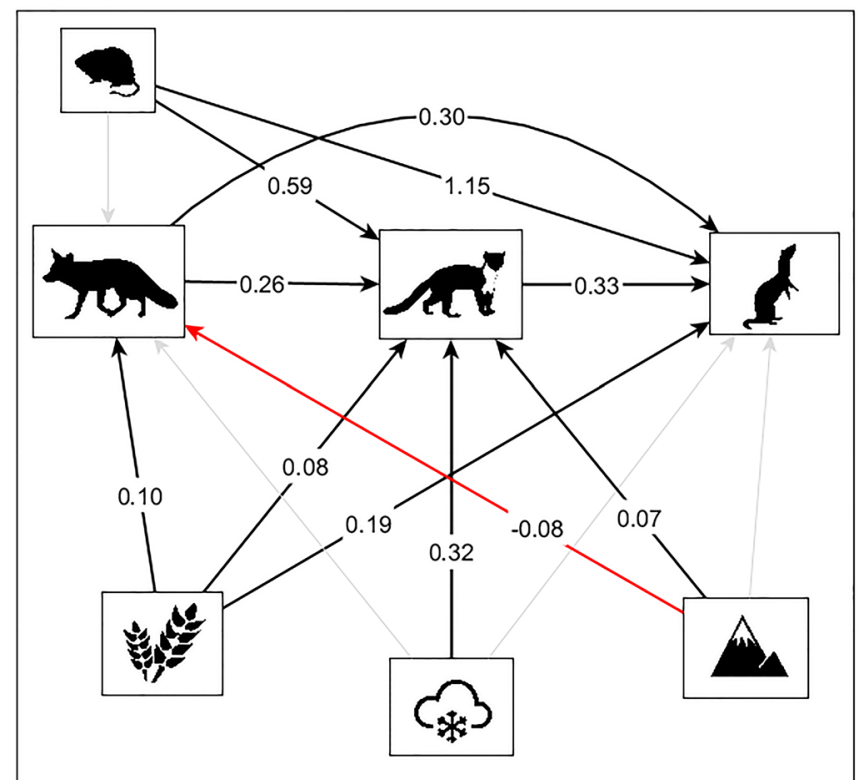

Fig. 4 Final structural equation model (SEM) evaluating the relationship between predators, rodent growth, and environmental variables. a The coefficients for the direct associations (i.e., without the interaction with rodent growth). b The coefficients for the interaction with rodent growth (i.e., how rodent growth affects the direct paths in a). (b)

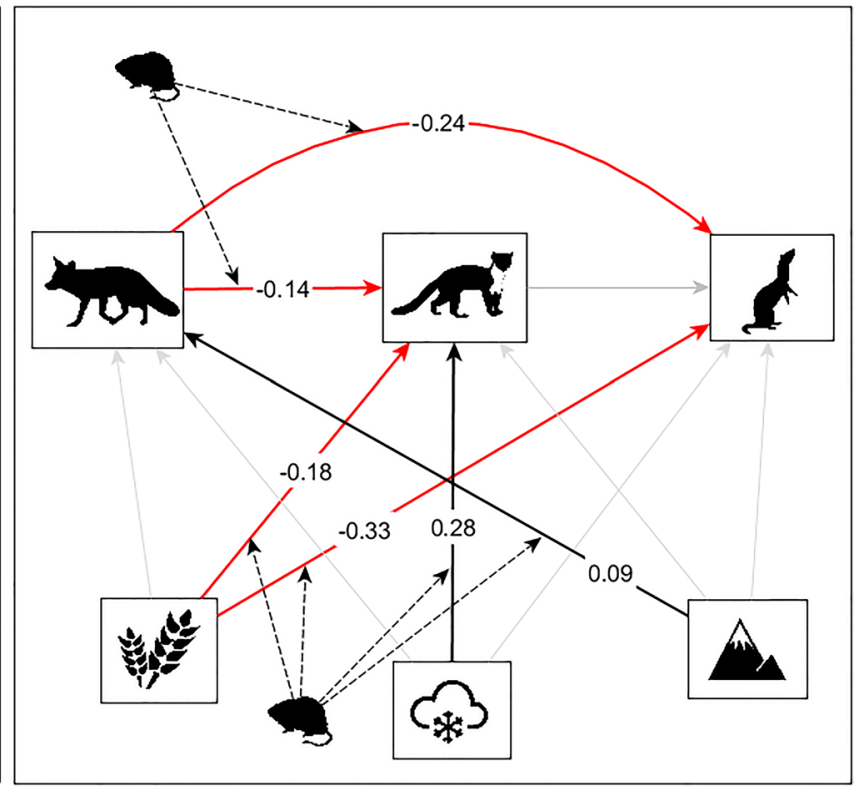

Values along arrows represent the relative magnitudes of positive (black) and negative (red) standardized path coefficients. Path coefficients whose $80 \%$ CRI overlap 0 are represented by gray arrows without values
Fig. 5 Posterior parameter distributions for the final structural equation model (Fig. 4) explaining direct associations and interactions of carnivores with rodent growth. The thick blue lines represent the $80 \%$ credible intervals of the posterior parameter distributions, and the thin lines represent the $95 \%$ credible intervals. Circles represent the posterior means

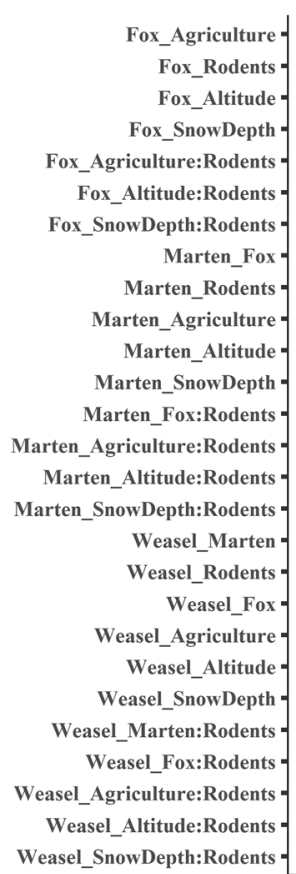

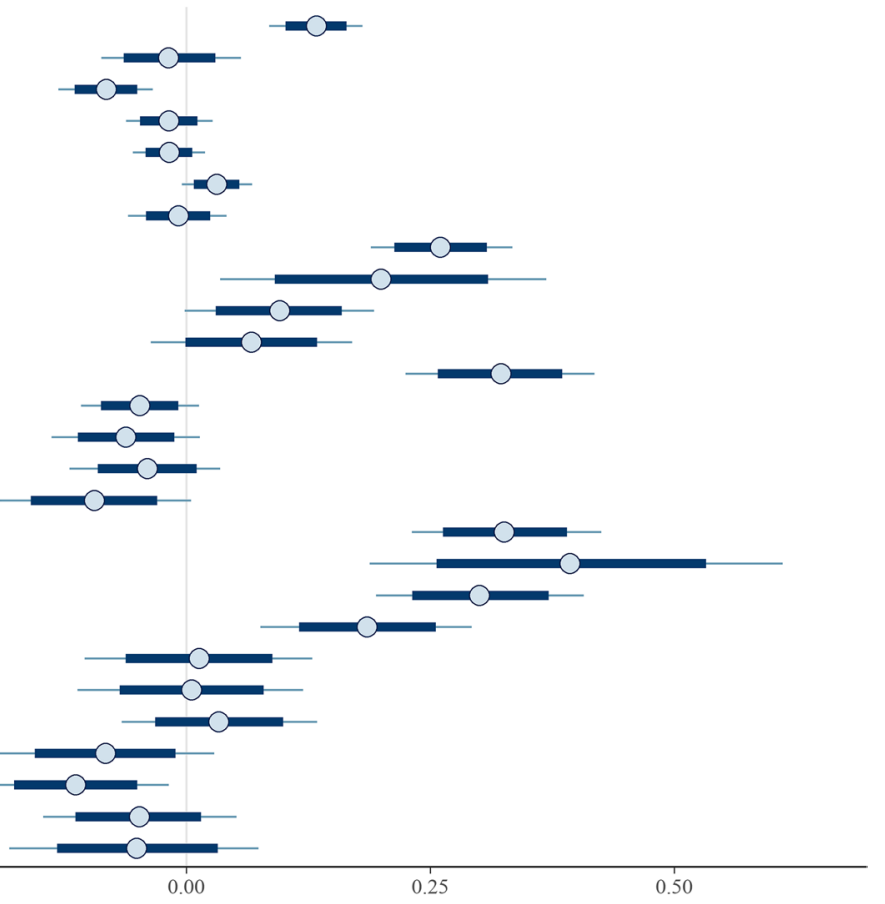

interactions within the predator guild (Greenville et al. 2014; Henden et al. 2009a; Stoessel et al. 2018).

There was a strong positive association between weasels and small rodent increase. This is in line with other studies and it highlights their degree of rodent specialization (Hanski et al. 1993; Jedrzejewski et al. 1995; Korpimäki et al. 1991). Pine marten also showed a positive association with rodent growth, but red fox was not significantly affected. 
Since red fox, pine marten, and weasels all rely largely on rodents as their main prey, especially in Scandinavia, they are expected to show functional and numerical responses to rodent fluctuations (Hanski et al. 1991). The red fox is considered a classic generalist predator that consumes small rodents when they are at high densities and switches to alternative prey when rodents decline (Angelstam et al. 1984; Jedrzejewski and Jedrzejewska 1992). Therefore, red fox abundance is not expected to follow rodent fluctuations as closely as the specialist predators, and alternative resources such as woodland grouse (subfamily Tetraoninae), mountain hares (Lepus timidus), ungulate carcasses, and anthropogenic food play an important role in stabilizing red fox population at low rodent densities (Carricondo-Sanchez et al. 2016; Killengreen et al. 2011; Selås and Vik 2006; Willebrand et al. 2017). Weasels are strict rodent specialists that prey on small rodents regardless of their availability and, thus, their survival and reproduction is strongly influenced by rodent fluctuations (Jedrzejewski et al. 1995; Sundell et al. 2013), as confirmed in our study. Pine martens, on the other hand, can be considered intermediate, because they may specialize on a few prey items such as small rodents and squirrels, but they can also switch to alternative food resources if needed (e.g., eggs, small birds, and carcasses; Jedrzejewski et al. 1993; Pulliainen and Ollinmäki 1996). Therefore, their abundance may correlate with rodent cycles, but not to the same extent as weasels.

Regarding species interactions, the three predators were positively associated with each other, which is likely to be a result of similarities in habitat and diet requirements. Positive associations between negatively interacting species are probably facilitated by landscape heterogeneity and differences in activity patterns; i.e., species may coexist by using different microhabitats and temporal niches (Bischof et al. 2014; Lesmeister et al. 2015; Viota 2012). However, this positive association between predators was strongly influenced by rodent growth: pine marten and weasels were less likely to be associated with red fox when rodents were increasing. As a generalist predator, the red fox tends to prey mostly on rodents during the increasing phase of the cycle. In addition, Dell'Arte et al. (2007) found that red foxes increased their predation on small mustelids when vole densities were high. Consequently, subdominant specialist predators like weasels are expected to experience higher impacts of interference competition when resource densities are high (Dell'Arte et al. 2007; Henden et al. 2009a). Our results suggest that under such conditions, avoidance of larger and dominant predators may drive smaller competitors to use less optimal habitats. This would explain the weaker association that we observed between red fox and mustelids during the increasing phase of the rodent cycle.

Conversely, during the decrease phase of the rodent cycle, pine marten and weasels showed a stronger spatial association with red fox. Under a low prey resource scenario, smaller predators are usually superior in exploitative competition because of their enhanced ability to hunt specific prey (King 1989). Furthermore, pine marten and weasels are considered very efficient predators, even under an increased risk of competitive interference, because of their ability to access food in a diversity of habitat strata (Bischof et al. 2014; Brainerd and Rolstad 2002). Hence, they can afford to select areas preferred by rodents during low phases despite an increased spatial overlap and potential competition with red fox. This has been shown for other pairs of sympatric carnivores such us red fox and arctic fox (Vulpes lagopus), which were positively associated only during the low phase of the rodent cycle (Stoessel et al. 2018). Moreover, under a scenario of resource constraints and stronger spatial associations among competing predators, it is likely that habitat heterogeneity and temporal niche segregation play an even more important role to facilitate species coexistence (Bischof et al. 2014; de Satge et al. 2017; Linnell and Strand 2000; Sergio et al. 2003).

All predators were positively associated with agriculture land, which represents productive areas where small rodents are abundant and easily accessible (Panzacchi et al. 2010). These areas are also associated with human settlements and anthropogenic food, which is an important alternative food source for red foxes (Killengreen et al. 2011; Rosalino et al. 2010). Therefore, productive agricultural lands might offer a continuous source of food for red foxes throughout the year, with anthropogenic food being an alternative resource when rodent numbers decrease. This could explain why the positive association between red fox and agricultural lands is not affected by changes in rodent abundance. Pine marten and weasels, however, were more strongly associated with agricultural land during the decrease phase of the rodent cycle. As rodent specialists, weasels tend to concentrate their foraging activity in more productive areas such as agricultural lands when food availability is low (Klemola et al. 1999), thus increasing their spatial association with red fox during low rodent phases.

Altitude had a negative effect on red fox abundance, yet this negative association was influenced by rodent growth. During the increase phase of the rodent cycle, red fox showed a positive association with altitude. Andreassen et al. (2019) found that vole amplitudes were higher at higher elevations, with greater maximum vole densities at high elevations during peak years. This could explain why red foxes move to higher elevations during the increase phase of the rodent cycle, since rodents seem to be more abundant at higher altitudes during this phase of the cycle. Furthermore, red foxes are expected to switch to alternative food sources when rodent abundance decreases, and this may induce a shift in habitat use towards lower altitudes close to human activities (Š́lek et al. 2015).

Pine marten was the only predator to show a positive association with snow depth, and this association was even 
stronger during the increase phase of the rodent cycle. Pine marten seems to be more efficient in killing prey under the snow than red fox (Willebrand et al. 2017); therefore, they might use deep snow areas as a way of reducing interference competition when the overlap with red fox is higher. Alternatively, snow depth may be correlating with some other variable that we did not measure, with positive effects on pine marten abundance. Although some studies indicate that snow depth reduces red fox hunting success and probability to survive (Jedrzejewski and Jedrzejewska 1992; Lindström and Hörnfeldt 1994; Selås and Vik 2006; Willebrand et al. 2017), we did not find any particular association between red fox and snow depth. However, we did not measure snow compaction, which may affect predators' habitat use (Pozzanghera et al. 2016).

Predator interactions tend to be very complex, as they are influenced by several intrinsic and extrinsic factors. Moreover, complexity increases when we consider the effects of a cyclic shared prey and strong seasonality. Here, we show that different phases of the prey cycle drive changes in the interactions among sympatric carnivores.

The results of this study are restricted to the interactions of a specific guild of predators in a boreal ecosystem. However, we believe that extrapolation on the functioning of other communities in which several predators share a cyclic prey can be made with caution. Under a climate change scenario, small mammal cyclic fluctuations are expected to change, for example, due to changes in seasonality. Given our results, we could speculate that these changes might alter the dynamics of the predator community by changing top-down and bottom-up interactions. This study highlights the importance of taking into account prey dynamics when studying interspecific interactions among predators. It also shows the need for monitoring in order to anticipate undesirable outcomes such as enhanced generalist predator abundances to the detriment of specialists predators.

Supplementary Information The online version contains supplementary material available at https://doi.org/10.1007/s13364-021-00590-7.

Acknowledgements We thank Hedmark Chapter of the Norwegian Association and Anglers and all the volunteers for collecting snow tracking data.

Author contribution Rocio Cano-Martinez, David CarricondoSanchez, and Morten Odden contributed to the study conception and design. Analysis was performed by Rocio Cano-Martinez, David Carricondo-Sanchez, and Olivier Devineau. The first draft of the manuscript was written by Rocio Cano-Martinez and all authors commented on previous versions of the manuscript. All authors read and approved the final manuscript.

Funding Open Access funding provided by Inland Norway University of Applied Sciences. The data collection was funded by the Norwegian Environment Agency.
Data availability The data supporting the analyses will be available at the Dryad Digital Repository upon the acceptance of the manuscript.

Code availability Not applicable.

\section{Declarations}

Ethics approval Not applicable.

Consent to participate Not applicable.

Consent for publication Not applicable.

Conflict of interest The authors declare no competing interests.

Open Access This article is licensed under a Creative Commons Attribution 4.0 International License, which permits use, sharing, adaptation, distribution and reproduction in any medium or format, as long as you give appropriate credit to the original author(s) and the source, provide a link to the Creative Commons licence, and indicate if changes were made. The images or other third party material in this article are included in the article's Creative Commons licence, unless indicated otherwise in a credit line to the material. If material is not included in the article's Creative Commons licence and your intended use is not permitted by statutory regulation or exceeds the permitted use, you will need to obtain permission directly from the copyright holder. To view a copy of this licence, visit http://creativecommons.org/licenses/by/4.0/.

\section{References}

Andreassen HP, Johnsen K, Joncour B, Neby M, Odden M (2019) Seasonality shapes the amplitude of vole population dynamics rather than generalist predators. Oikos 129:117-123. https://doi. org/10.1111/oik.06351

Angelstam P, Lindstrom E, Widen P (1984) Role of predation in short-term population fluctuations of some birds and mammals in Fennoscandia. Oecologia 62:199-208. https://doi.org/10. 1007/bf00379014

Bagchi S, Ritchie M (2012) Body size and species coexistence in consumer-resource interactions: a comparison of two alternative theoretical frameworks. Thyroid Res 5:141-151. https://doi. org/10.1007/s12080-010-0105-x

Balme GA, Pitman RT, Robinson HS, Miller JRB, Funston PJ, Hunter LTB (2017) Leopard distribution and abundance is unaffected by interference competition with lions. Behav Ecol 28:1348-1358. https://doi.org/10.1093/beheco/arx098

Bischof R, Ali H, Kabir M, Hameed S, Nawaz MA (2014) Being the underdog: an elusive small carnivore uses space with prey and time without enemies. J Zool 293:40-48. https://doi.org/ $10.1111 /$ jzo. 12100

Brainerd SM, Rolstad J (2002) Habitat selection by Eurasian pine martens Martes martes in managed forests of southern boreal Scandinavia. Wildl Biol 8(289-297):289

Breisjøberget JI, Odden M, Wegge P, Zimmermann B, Andreassen $H$ (2018) The alternative prey hypothesis revisited: still valid for willow ptarmigan population dynamics. PLoS ONE 13:e0197289. https://doi.org/10.1371/journal.pone.0197289

Brommer J, Pietiäinen H, Ahola K, Karell P, Karstinen T, Kolunen H (2010) The return of the vole cycle in southern Finland refutes the generality of the loss of cycles through 'climatic forcing.' 
Glob Change Biol 16:577-586. https://doi.org/10.1111/j.13652486.2009.02012.x

Bürkner P-C (2017) brms: Bayesian regression models using 'Stan.' J Stat Softw 80:1-28. https://doi.org/10.18637/jss.v080.i01

Carricondo-Sánchez D, Samelius G, Odden M, Willebrand T (2016) Spatial and temporal variation in the distribution and abundance of red foxes in the Tundra and Taiga of Northern Sweden. Eur J Wildl Res 62:211-218. https://doi.org/10.1007/ s10344-016-0995-z

de Satge J, Teichman K, Cristescu B (2017) Competition and coexistence in a small carnivore guild. Oecologia 184:873-884. https:// doi.org/10.1007/s00442-017-3916-2

Dell'Arte GL, Laaksonen T, Norrdahl K, Korpimäki E (2007) Variation in the diet composition of a generalist predator, the red fox, in relation to season and density of main prey. Acta Oecologica 31:276-281. https://doi.org/10.1016/j.actao.2006.12.007

Elmhagen B, Kindberg J, Hellstrom P, Angerbjorn A (2015) A boreal invasion in response to climate change? Range shifts and community effects in the borderland between forest and tundra. Ambio 44(Suppl 1):39-50. https://doi.org/10.1007/ s13280-014-0606-8

Elmhagen B, Rushton SP (2007) Trophic control of mesopredators in terrestrial ecosystems: top-down or bottom-up? Ecol Lett 10:197-206. https://doi.org/10.1111/j.1461-0248.2006.01010.x

Elton C, Nicholson M (1942) The ten-year cycle in numbers of the lynx in Canada. J Anim Ecol 11:215-244. https://doi.org/10. 2307/1358

ESRI (2014) ArcGIS desktop: release 10.3. Environmental Systems Research Institute, Redlands, CA

Gauthier S, Bernier P, Kuuluvainen T, Shvidenko AZ, Schepaschenko DG (2015) Boreal forest health and global change. Science 349:819-822. https://doi.org/10.1126/science.aaa9092

Gelman A, Goodrich B, Gabry J, Vehtari A (2018) R-squared for Bayesian regression models. The American Statistician. 73:1-6

Gelman A, Rubin DB (1992) Inference from iterative simulation using multiple sequences. Stat Sci 7:457-472

Grace JB (2006) Structural equation modeling and natural systems. Cambridge University Press, Cambridge, UK. https://doi.org/10. 1017/CBO9780511617799

Grace JB, Schoolmaster DR Jr, Guntenspergen GR, Little AM, Mitchell BR, Miller KM, Schweiger EW (2012) Guidelines for a graph-theoretic implementation of structural equation modeling. Ecosphere 3:1-44. https://doi.org/10.1890/es12-00048.1

Greenville AC, Wardle GM, Tamayo B, Dickman CR (2014) Bottomup and top-down processes interact to modify intraguild interactions in resource-pulse environments. Oecologia 175:1349-1358. https://doi.org/10.1007/s00442-014-2977-8

Hanski I, Hansson L, Henttonen H (1991) Specialist predators, generalist predators, and the microtine rodent cycle. J Anim Ecol 60:353-367. https://doi.org/10.2307/5465

Hanski I, Turchin P, Korpimäki E, Henttonen H (1993) Population oscillations of boreal rodents: regulation by mustelid predators leads to chaos. Nature 364:232-235. https://doi.org/10.1038/364232a0

Hansson L, Henttonen H (1985) Gradients in density variations of small rodents: the importance of latitude and snow cover. Oecologia 67:394-402. https://doi.org/10.1007/bf00384946

Helldin JO (1999) Diet, body condition, and reproduction of Eurasian pine martens Martes martes during cycles in microtine density. Ecography 22:324-336. https://doi.org/10.1111/j.1600-0587.1999. tb00508.x

Henden J-A, Ims R, Yoccoz N, Hellström P, Angerbjörn A (2009a) Strength of asymmetric competition between predators in food webs ruled by fluctuating prey: the case of foxes in tundra. Oikos 119:27-34. https://doi.org/10.1111/j.1600-0706.2009.17604.x

Henden J-A, Yoccoz N, Ims R, Bårdsen B-J, Angerbjörn A (2009b) Phase-dependent effect of conservation efforts in cyclically fluctuating populations of Arctic fox (Vulpes lagopus). Biol Cons 142:2586-2592. https://doi.org/10.1016/j.biocon.2009.06.005

Hersteinsson P, MacDonald DW (1992) Interspecific competition and the geographical distribution of red and Arctic foxes Vulpes vulpes and Alopex lagopus. Oikos 64:505-515. https://doi.org/10.2307/ 3545168

Hilbe JM (2014) Modeling count data. Cambridge University Press, Cambridge. https://doi.org/10.1017/CBO9781139236065

Hörnfeldt B, Hipkiss T, Eklund U (2005) Fading out of vole and predator cycles? Proceedings of the Royal Society B: Biological Sciences 272:2045-2049. https://doi.org/10.1098/rspb.2005.3141

Hunter JS, Caro T (2008) Interspecific competition and predation in American carnivore families. Ethol Ecol Evol 20:295-324. https:// doi.org/10.1080/08927014.2008.9522514

Ims RA, Fuglei E (2005) Trophic interaction cycles in tundra ecosystems and the impact of climate change. Bioscience 55:311-322. https://doi.org/10.1641/0006-3568(2005)055[0311:TICITE]2.0. $\mathrm{CO} ; 2$

Jahren T (2017) The role of nest predation and nest predators in population declines of capercaillie and black grouse. Dissertation, Inland Norway University of Applied Sciences

Jahren T, Odden M, Linnell JDC, Panzacchi M (2020) The impact of human land use and landscape productivity on population dynamics of red fox in southeastern Norway. Mamm Res 65:503-516. https://doi.org/10.1007/s13364-020-00494-y

Jedrzejewski W, Jedrzejewska B (1992) Foraging and diet of the red fox Vulpes vulpes in relation to variable food resources in Bialowieza National Park, Poland. Ecography 15:212-220

Jedrzejewski W, Jedrzejewska B, Szymura L (1995) Weasel population response, home range, and predation on rodents in a deciduous forest in Poland. Ecology 76:179-195. https://doi.org/10.2307/ 1940640

Jedrzejewski W, Jedrzejewska B, Szynura A (1989) Food niche overlaps in a winter community of predators in the Bialowieza Primeval Forest, Poland. Acta Theriol 34:487-496

Jedrzejewski W, Zalewski A, Jędrzejewska B (1993) Foraging by pine marten Martes martes in relation to food resources in Białowieża National Park, Poland. Acta Theriol 38:405-426. https://doi.org/ 10.4098/AT.arch.93-32

Killengreen ST, Lecomte N, Ehrich D, Schott T, Yoccoz NG, Ims RA (2011) The importance of marine vs. human-induced subsidies in the maintenance of an expanding mesocarnivore in the Arctic tundra. J Anim Ecol 80:1049-1060. https://doi.org/10.1111/j.13652656.2011.01840.x

King CM (1989) The advantages and disadvantages of small size to weasels, Mustela species. In: Gittleman JL (ed) Carnivore behavior, ecology, and evolution. Cornell University Press, Ithaca, NY, pp 302-334. https://doi.org/10.1007/978-1-4757-4716-4_12

King CM, Moors PJ (1979) On co-existence, foraging strategy and the biogeography of weasels and stoats (Mustela nivalis and $M$. erminea) in Britain. Oecologia 39:129-150. https://doi.org/10. 1007/BF00348064

King CM, Powell RA (2007a) The impact of predation by weasels on populations of natural prey. In: King CM, Powell RA (eds) The natural history of weasels and stoats: ecology, behavior, and management, 2nd edn. Oxford University Press, Oxford, pp 137-159

King CM, Powell RA (2007b) The natural history of weasels and stoats: ecology, behavior, and management, 2nd edn. Oxford University Press, Oxford

Klemola T, Korpimäki E, Norrdahl K, Tanhuanpää M, Koivula M (1999) Mobility and habitat utilization of small mustelids in relation to cyclically fluctuating prey abundances. Ann Zool Fenn 36:75-82

Korpimäki E, Krebs C (1996) Predation and population cycles of small mammals. Bioscience 46:754-764. https://doi.org/10.2307/13128 51 
Korpimäki E, Norrdahl K, Tuija R-J (1991) Responses of stoats and least weasels to fluctuating food abundances: is the low phase of the vole cycle due to mustelid predation? Oecologia 88:552-561

Krebs CJ, Myers JH (1974) Population cycles in small mammals. Adv Ecol Res 8:267-399. https://doi.org/10.1016/S0065-2504(08) 60280-9

Kurki S, Nikula A, Helle P, Linden H (1998) Abundances of red fox and pine marten in relation to the composition of boreal forest landscapes. J Anim Ecol 67:874-886. https://doi.org/10.1046/j.13652656.1998.6760874.x

Laundré JW, Hernández L, Altendorf KB (2001) Wolves, elk, and bison: reestablishing the "landscape of fear" in Yellowstone National Park, U.S.A. Can J Zool 79:1401-1409. https://doi.org/10.1139/z01-094

Lesmeister D, Nielsen C, Schauber E, Hellgren E (2015) Spatial and temporal structure of a mesocarnivore guild in Midwestern North America. Wildl Monogr 191:1-61. https://doi.org/10.1002/wmon. 1015

Li D, Wu S, Liu L, Zhang Y, Li S (2018) Vulnerability of the global terrestrial ecosystems to climate change. Glob Change Biol 24:40954106. https://doi.org/10.1111/gcb.14327

Lindén H (1988) Latitudinal gradients in predator-prey interactions, cyclicity and synchronism in voles and small game populations in Finland. Oikos 52:341-349. https://doi.org/10.2307/3565208

Lindström ER, Hörnfeldt B (1994) Vole cycles, snow depth and fox predation. Oikos 70:156-160. https://doi.org/10.2307/3545711

Linnell J, Strand O (2000) Interference interactions, co-existence and conservation of mammalian carnivores. Divers Distrib 6:169-176. https://doi.org/10.1046/j.1472-4642.2000.00069.x

Morin PJ (2011) Competition: mechanisms, models, and niches. In: Morin PJ (ed) Community ecology. John Wiley \& Sons Ltd, US, pp 24-57. https://doi.org/10.1002/9781444341966.ch2

Myers JH (1988) Can a general hypothesis explain population cycles of forest Lepidoptera? Adv Ecol Res 18:179-242. https://doi.org/ 10.1016/S0065-2504(08)60181-6

Norrdahl K (1995) Population cycles in northern small mammals. Biol Rev 70:621-637

O’Mahony D, Lambin X, MacKinnon JL, Chris FC (1999) Fox predation on cyclic field vole populations in Britain. Ecography 22:575-581

Palomares F, Caro TM (1999) Interspecific killing among mammalian carnivores. Am Nat 153:492-508. https://doi.org/10.1086/303189

Palomares F, Fernández N, Roques S, Chávez C, Silveira L, Keller C, Adrados B (2016) Fine-scale habitat segregation between two ecologically similar top predators. PLoS ONE 11:e0155626. https:// doi.org/10.1371/journal.pone.0155626

Palomares F, Ferreras P, Travaini A, Delibes M (1998) Co-existence between Iberian lynx and Egyptian mongooses: estimating interaction strength by structural equation modelling and testing by an observational study. J Anim Ecol 67:967-978

Panzacchi M, Linnell JDC, Melis C, Odden M, Odden J, Gorini L, Andersen R (2010) Effect of land-use on small mammal abundance and diversity in a forest-farmland mosaic landscape in south-eastern Norway. For Ecol Manage 259:1536-1545. https:// doi.org/10.1016/j.foreco.2010.01.030

Pedersen S, Odden M, Pedersen HC (2017) Climate change induced molting mismatch? Mountain hare abundance reduced by duration of snow cover and predator abundance. Ecosphere 8:e01722. https://doi.org/10.1002/ecs2.1722

Polis GA, Holt RD (1992) Intraguild predation: the dynamics of complex trophic interactions. Trends Ecol Evol 7:151-154. https://doi. org/10.1016/0169-5347(92)90208-s

Pozzanghera CB, Sivy KJ, Lindberg MS, Prugh LR (2016) Variable effects of snow conditions across boreal mesocarnivore species. Can J Zool 94:697-705. https://doi.org/10.1139/cjz-2016-0050
Pulliainen E, Ollinmäki P (1996) A long-term study of the winter food niche of the pine marten Martes martes in northern boreal Finland. Acta Theriol 41:337-352. https://doi.org/10.4098/AT.arch. 96-33

Randa LA, Cooper DM, Meserve PL, Yunger JA (2009) Prey switching of sympatric canids in response to variable prey abundance. J Mammal 90:594-603. https://doi.org/10.1644/ 08-MAMM-A-092R1.1

Ranta E, Lindstrom J, Linden H (1995) Synchrony in tetraonid population dynamics. J Anim Ecol 64:767-776. https://doi.org/10.2307/ 5855

Rosalino LM, Sousa M, Pedroso NM, Basto MP, Rosário J, Santos MJ, Loureiro F (2010) The influence of food resources on red fox local distribution in a mountain area of the Western Mediterranean. Vie Et Milieu-Life and Environment 60(1):39-45

Šálek M, Drahníková L, Tkadlec E (2015) Changes in home range sizes and population densities of carnivore species along the natural to urban habitat gradient. Mammal Rev 45:1-14. https://doi.org/10. 1111/mam.12027

Schoener TW (1974) Resource partitioning in ecological communities. Science 185:27-39. https://doi.org/10.1126/science.185.4145.27

Selås V, Vik JO (2006) Possible impact of snow depth and ungulate carcasses on red fox (Vulpes vulpes) populations in Norway, 1897-1976. J Zool 269:299-308. https://doi.org/10.1111/j.14697998.2006.00048.x

Sergio F, Marchesi L, Pedrini P (2003) Spatial refugia and the coexistence of a diurnal raptor with its intraguild owl predator. J Anim Ecol 72:232-245. https://doi.org/10.1046/j.1365-2656.2003. 00693.x

Silverman BW (1986) Density estimation for statistics and data analysis. Chapman \& Hall, London

Stoessel M, Elmhagen B, Vinka M, Hellström P, Angerbjörn A (2018) The fluctuating world of a tundra predator guild: bottom-up constraints overrule top-down species interactions in winter. Ecography 42:488-499. https://doi.org/10.1111/ecog.03984

Storch I, Lindström E, de Jounge J (1990) Diet and habitat selection of the pine marten in relation to competition with the red fox. Acta Theriol 35:311-320. https://doi.org/10.4098/AT.arch.90-36

Sundell J, O'Hara Robert B, Helle P, Hellstedt P, Henttonen H, Pietiäinen $H$ (2013) Numerical response of small mustelids to vole abundance: delayed or not? Oikos 122:1112-1120. https://doi.org/ 10.1111/j.1600-0706.2012.00233.x

Tovmo M, Brøseth H (2014) Gauperegistrering i utvalgte fylker 2014. - NINA Rapport 1054. $27 \mathrm{~s}$

Vehtari A, Gabry J, Magnusson M, Yao Y, Gelman A (2019) "loo: efficient leave-one-out cross-validation and WAIC for Bayesian models." R package version 2.1.0. https://mc-stan.org/loo/

Viota M (2012) Shift in microhabitat use as a mechanism allowing the coexistence of victim and killer carnivore predators. Open J Ecol 02:115-120. https://doi.org/10.4236/oje.2012.23014

Walton Z, Samelius G, Odden M, Willebrand T (2017) Variation in home range size of red foxes Vulpes vulpes along a gradient of productivity and human landscape alteration. PLoS ONE 12:e0175291. https://doi.org/10.1371/journal.pone.0175291

Watson A, Moss R, Rae S (1998) Population dynamics of Scottish rock ptarmigan cycles. Ecology 79:1174-1192. https://doi.org/ $10.2307 / 176735$

Willebrand T, Willebrand S, Jahren T, Marcström V (2017) Snow tracking reveals different foraging patterns of red foxes and pine martens. Mamm Res 62:331-340. https://doi.org/10.1007/ s13364-017-0332-2

Publisher's note Springer Nature remains neutral with regard to jurisdictional claims in published maps and institutional affiliations. 